\title{
Role of Dutasteride in Pre-Clinical ETS Fusion-Positive Prostate Cancer Models
}

\author{
Bushra Ateeq, ${ }^{1,2}$ Adaikkalam Vellaichamy, ${ }^{1,2}$ Scott A. Tomlins, ${ }^{1,2}$ Rui Wang, ${ }^{1,2}$ Qi Cao, ${ }^{1,2}$ \\ Robert J. Lonigro, ${ }^{1,3}$ Kenneth J. Pienta, ${ }^{1,3,4}$ and Sooryanarayana Varambally ${ }^{1,2,3 *}$ \\ 'Michigan Center for Translational Pathology, University of Michigan Medical School, Ann Arbor, Michigan \\ ${ }^{2}$ Department of Pathology, University of Michigan Medical School, Ann Arbor, Michigan \\ ${ }^{3}$ Comprehensive Cancer Center, University of Michigan Medical School, Ann Arbor, Michigan \\ ${ }^{4}$ Internal Medicine, University of Michigan Medical School, Ann Arbor, Michigan
}

\begin{abstract}
BACKGROUND. Androgens play a crucial role in prostate cancer, hence the androgenic pathway has become an important target of therapeutic intervention. Previously we discovered that gene fusions between the $5^{\prime}$-untranslated region of androgen regulated gene TMPRSS2 and the ETS transcription factor family members were present in a majority of the prostate cancer cases. The resulting aberrant overexpression of ETS genes drives tumor progression.

METHODS. Here, we evaluated the expression levels of $5 \alpha$-reductase isoenzymes in prostate cancer cell lines and tissues. We tested the effect of dutasteride, a $5 \alpha$-reductase inhibitor, in TMPRSS2-ERG fusion-positive VCaP cell proliferation and cell invasion. We also evaluated the effect of dutasteride on the TMPRSS2-ERG fusion gene expression. Finally, we tested dutasteride alone or in combination with an anti-androgen in VCaP cell xenografts tumor model.

RESULTS. Our data showed that $5 \alpha$-reductase SRD5A1 and SRD5A3 isoenzymes that are responsible for the conversion of testosterone to DHT, are highly expressed in metastatic prostate cancer compared to benign and localized prostate cancer. Dutasteride treatment attenuated $\mathrm{VCaP}$ cell proliferation and invasion. VCaP cells pre-treated with dutasteride showed a reduction in ERG and PSA expression. In vivo studies demonstrated that dutasteride in combination with the anti-androgen bicalutamide significantly decreased tumor burden in VCaP cell xenograft model.

CONCLUSIONS. Our findings suggest that dutasteride can inhibit ERG fusion-positive cell growth and in combination with anti-androgen, significantly reduce the tumor burden. Our study suggests that anti-androgens used in combination with dutasteride could synergistically augment the therapeutic efficacy in the treatment of ETS-positive prostate cancer. Prostate 72: 1542-1549, 2012. (C) 2012 Wiley Periodicals, Inc.
\end{abstract}

KEY WORDS: $\quad$ prostate cancer; gene fusion; TMPRSS2-ERG; $5 \alpha$-reductase; dutasteride

\section{INTRODUCTION}

A majority of prostate cancer patients harbor gene fusions involving androgen regulated promoters and members of the ETS family of transcription factors [1-3] that are known to play a critical role in prostate tumorigenesis. Overexpression of ERG in primary or immortalized benign prostate epithelial cells induces an invasion-associated transcriptional program [4]. Conversely, ERG knockdown in VCaP cells, an androgen-sensitive metastatic prostate cancer cell line harboring the TMPRSS2-ERG gene fusion, decreases cell
Grant sponsor: GSK; Grant sponsor: Genentech Foundation Postdoctoral Fellowship; Grant sponsor: Expedition Inspiration.

Adaikkalam Vellaichamy present address is Department of Nanomedicine, The Methodist Hospital Research Institute, Houston, TX 77030.

*Correspondence to: Dr. Sooryanarayana Varambally, PhD, Department of Pathology, University of Michigan Medical School, Traverwood IV, Suite 100, 2900 Huron Parkway, Ann Arbor, MI 481090602. E-mail: soory@med.umich.edu

Received 16 December 2011; Accepted 13 February 2012 DOI 10.1002/pros.22509

Published online 13 March 2012 in Wiley Online Library (wileyonlinelibrary.com). 
proliferation and tumor growth in mice [5]. Other studies demonstrated that VCaP cells and immortalized benign prostate epithelial cells (RWPE-1) overexpressing ERG directly engage components of the plasminogen activation pathway to mediate cellular invasion, potentially representing a downstream $E R G$ target susceptible to therapeutic intervention [4]. Furthermore, transgenic mice expressing the ERG gene fusion product under androgen regulation develop mouse prostatic intraepithelial neoplasia (mPIN), a precursor lesion of prostate cancer [4,6,7], and when combined with other relevant genomic lesions such as loss of PTEN, result in the development of invasive carcinoma [7]. Recently, we showed that ERG binds to androgen receptor $(\mathrm{AR})$ and disrupts the regulation of a majority of its target genes. In addition, ERG activates the polycomb protein, EZH2, facilitating a stemcell-like dedifferentiation program, suggesting that TMPRSS2-ERG plays a key role in cancer by abrogating lineage-specific differentiation of the prostate [8].

Androgen-AR axis plays a critical role in prostate tumorigenesis, thus inhibition of AR activity has been a major therapeutic strategy for prostate cancer treatment. Anti-androgens that block AR function include bicalutamide (Casodex), flutamide, nilutamide, and the steroidal anti-androgen cyproterone acetate [9]. Another potent AR inhibitor, apregnenolone-derived compound abiraterone, renders both potency and selectivity in CYP17 inhibition and has demonstrated efficacy in reducing the weights of androgen-dependent organs, such as prostate, seminal vesicles, and testes [10]. Although responding initially to androgen deprivation therapy by depletion of gonadal testosterone (T), metastatic tumors almost invariably develop into castration-resistant prostate cancer (CRPC). AR amplification, gain-of-function mutations, and novel splice variant expression are thought to be responsible for this resistance [11]. The development of CRPC is also dependent upon the intratumoral generation of the potent androgen, dihydrotestosterone (DHT). As part of the androgen axis, the enzyme $5 \alpha$-reductase is responsible for the conversion of circulating $\mathrm{T}$ into DHT $[12,13]$ and in CRPC, adrenal androgens are converted to DHT by these enzymes. Three $5 \alpha$-reductase isoforms, SRD5A1, SRD5A2, and SRD5A3 have been characterized in the prostate [14]. In CRPC, SRD5A1 is overexpressed and a recent study indicated that SRD5A1 bypasses $\mathrm{T}$ and instead uses androstenedione as a substrate for $5 \alpha$-reduction to produce $5 \alpha$ androstanedione, which is then converted to DHT [15]. Inhibitors of $5 \alpha$-reductases block the conversion of $\mathrm{T}$ to the more potent androgen, DHT resulting in reduced androgenic activity in the prostate. $5 \alpha$-Reductase inhibitors such as finasteride and dutasteride are commonly used in cases of prostatic hyperplasia [16]. Recent report from a clinical trial suggested that dutasteride could prove beneficial for low-risk prostate cancer patients [17]. Furthermore, patients successfully treated with high doses of dutasteride were predominantly negative for TMPRSS2ERG genetic rearrangement [18].

Since androgen induces the expression of TMPRSS2-ERG, in the present study we investigated the effect of dutasteride on the expression of ERG as well as cellular phenotypes of the TMPRSS2-ERG rearrangement-positive prostate cancer cell line, $\mathrm{VCaP}$. Results from our study suggest that dual $5 \alpha$-reductase inhibitor, dutasteride, inhibits the expression of TMPRSS2-ERG in vitro under androgen-deprived condition. We also demonstrate that dutasteride, in combination with bicalutamide, leads to greater reduction in VCaP tumor burden than either inhibitor alone. Thus, our study provides pre-clinical evidence for a potential therapeutic strategy for the treatment of ETS fusion-positive prostate cancer.

\section{MATERIALS AND METHODS}

\section{Cell Lines, Tissue Samples, and DutasterideTreatments}

The VCaP prostate cancer cell line was derived from a vertebral metastasis of a patient with castration resistant metastatic prostate cancer and was kindly provided by Kenneth Pienta (University of Michigan). VCaP cells were cultured in DMEM Glutamax medium supplemented with $10 \%$ fetal bovine serum (FBS; Invitrogen, Carlsbad, CA). LNCaP cells were purchased from the American Type Cell Culture (ATCC, used at passage number 30-40) and cultured in RPMI-1640 medium supplemented with 10\% FBS. Both cell lines were maintained in a $5 \% \mathrm{CO}_{2}, 95 \%$ airhumidified atmosphere at $37^{\circ} \mathrm{C}$. Prostate tissues were obtained from the radical prostatectomy series and the Rapid Autopsy Program, both of which are part of the University of Michigan Prostate Cancer Specialized Program of Research Excellence (S.P.O.R.E.) Tissue Core. All samples were collected with informed consent of the patients and prior institutional review board approval. For all tissue samples and cell lines, total RNA was isolated with Trizol reagent (Invitrogen) according to the manufacturer's instructions.

Various doses of dutasteride were used to test the proliferative response. Cells were washed and supplemented with phenol red-free medium containing 5\% charcoal dextran-treated FBS (Cambrex Corp., East Rutherford, NJ) for $48 \mathrm{hr}$ prior to androgen treatment. For fusion gene expression studies, cells were pre-incubated with dutasteride for $2 \mathrm{hr}$ and then treated with either T or DHT or dutasteride to test the effect of dutasteride on the conversion of T to DHT. 


\section{Cell Proliferation Assay}

Equal numbers of VCaP cells were plated and grown to $70 \%$ confluence before treatment with varying doses of dutasteride and/or T and DHT. Cells were trypsinized 48-hr post-treatment and triplicate cell counts were obtained at appropriate time points using a Coulter counter (Beckman Coulter, Fullerton, CA) as described previously [4].

\section{Boyden Chamber Matrigel Cell Invasion Assay}

Boyden chamber invasion assays were performed using VCaP cells treated with R1881, T, DHT, or dutasteride, either alone or in combination. Cells were seeded onto the basement membrane matrix (Millipore, Bedford, MA) present on the insert of a 24-well culture plate. FBS was added to the lower chamber as a chemoattractant. After $48 \mathrm{hr}$ the noninvading cells and EC matrix were gently removed with a cotton swab. Invasive cells located on the outer side of the chamber were stained with crystal violet and air-dried. For colorimetric assays, the inserts were destained with $150 \mu \mathrm{l}$ of $10 \%$ acetic acid and the absorbance was measured at $560 \mathrm{~nm}$ by a spectrophotometer (GE Healthcare, Piscataway, NJ) as described previously [19].

\section{Quantitative Real-Time PCR}

Quantitative PCR was performed using Power SYBR Green Mastermix (Applied Biosystems, Foster City, CA) on an Applied Biosystems 7300 Real Time PCR system as previously described [1,20]. All oligonucleotide primers were synthesized by Integrated DNA Technologies (IDT, Coralville, IA). All reactions were performed in duplicate unless otherwise indicated. HMBS was used as control. The sequences of the primers for the three SRD5A isoforms, fusion transcript TMPRSS2-ERG and GAPDH are listed below:

\section{SRD5A1}

Forward primer: 5'-CCTGTTTGTTCTTTGTTGATTGAA-3'

Reverse primer: 5'-CCAGATGAGATGATAAGGCAAAG-3'

SRD5A2

Forward primer: 5'-ATCTGAACATACAGAGCCCACAT- $3^{\prime}$

Reverse primer: $5^{\prime}$-ATCCTCAGACCTTTCAAGTTTCC $-3^{\prime}$

SRD5A3

Forward primer: 5'-TTTAATCAGGCCCTGTCTGC-3'

Reverse primer: 5'-GGGGTATAGAAATGGAATGGAGA-3'

TMPRSS2-ERG
Forward primer: 5'-TAGGCGCGAGCTAAGCAGGAG-3'

Reverse primer: 5'-GTAGGCACACTCAAACAACGACTGG-3'

GAPDH

Forward primer: $5^{\prime}$-TGCACCACCAACTGCTTAGC-3'

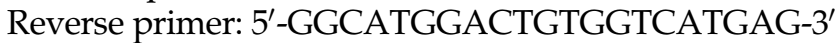

\section{Immunoblot Analysis}

Control and treated VCaP cells were lysed with NP-40 lysis buffer containing $50 \mathrm{mM}$ Tris- $\mathrm{HCl}, \mathrm{pH}$ 7.4, $1 \%$ Nonidet P-40 (Sigma, St. Louis, MO) and complete protease inhibitor cocktail (Roche, IN). Ten micrograms of protein extract were prepared in SDS sample buffer and electrophoresed onto a $4-12 \%$ NUPAGE Bis-Tris gel (Life Technologies, Grand Island, NY) under reducing conditions and transferred onto nitrocellulose membranes (GE Healthcare). The membrane was incubated for $1 \mathrm{hr}$ in blocking buffer [Tris-buffered saline with $0.1 \%$ Tween (TBS-T) and $5 \%$ non-fat dry milk] followed by the addition of ERG1 rabbit polyclonal antibody (1:500; Santa Cruz Biotechnology, Santa Cruz, CA) and PSA rabbit polyclonal antibody (Dako, Dako Denmark A/S 1:10,000) antibody and incubated overnight at $4^{\circ} \mathrm{C}$. After washing three times with TBS-T buffer, the membrane was incubated with horseradish peroxidase-linked donkey anti-rabbit IgG antibody (GE Healthcare) at a 1:5,000 dilution for $1 \mathrm{hr}$ at room temperature. The signals were visualized with the enhanced chemiluminescence detection system (GE Healthcare) and autoradiography. Rabbit anti-actin antibody (Sigma) was applied at 1:30,000 and served as loading control.

\section{VCaP-Luciferase Xenograft Model}

Two million prostate cancer VCaP cells overexpressing luciferase (VCaP-Luc) were resuspended in $100 \mu \mathrm{l}$ of saline with 50\% Matrigel (BD Biosciences, Mountain View, CA) and were subcutaneously implanted into the left flank region of the 4-week-old male Balb $\mathrm{C}$ nu/nu mice. Three weeks later mice $(\mathrm{n}=40)$ with palpable tumors were randomized into four groups, and were treated with dutasteride $(0.1 \mathrm{mg} / \mathrm{kg}$ body weight), bicalutamide $(12 \mathrm{mg} / \mathrm{kg}$ body weight), or a combination of both intraperitoneally daily five times a week. Growth in tumor volume was recorded weekly using digital calipers, and tumor volumes were calculated using the formula $(\pi / 6$; $\mathrm{L} \times \mathrm{W} 2$ ), where $\mathrm{L}=$ length of tumor and $\mathrm{W}=$ width. In vivo bioluminescent imaging was performed weekly using an IVIS-200 imaging system (Caliper Life Sciences, Hopkinton, MA). Fifteen minutes prior to imaging, mice were given $150 \mathrm{mg} / \mathrm{kg}$ of luciferin by 
intraperitoneal injection. All images were collected and analyzed by using Living Image software (Xenogen Corporation). All procedures involving mice were approved by the University Committee on Use and Care of Animals (UCUCA) at the University of Michigan and conform to all relevant regulatory standards.

\section{Statistical Analyses}

All data are presented as mean \pm SEM, and significance was determined by two-tailed Student's $t$-test.

\section{RESULTS}

\section{Expression of SRD5A Isoforms in Prostate Cell Lines and TumorTissues}

Quantitative RT-PCR was performed using RNA from androgen responsive prostate derived cell lines $\mathrm{LNCaP}$ and $\mathrm{VCaP}$ as well as normal and prostate tumor tissues to evaluate the expression of $S R D 5 A 1$, SRD5A2, and SRD5A3. SRD5A3 was highly expressed in both LNCaP (ETV1 rearrangement positive) and VCaP (TMPRSS2-ERG positive) cell lines, whereas $S R D 5 A 1$ expression was modestly elevated in $\mathrm{VCaP}$ cells only (Fig. 1A). Expression of SRD5A2 was very low in both cell lines (Fig. 1A).

Analysis of benign prostate and prostate cancer tissue samples revealed unique expression patterns of the three $5 \alpha$-reductase enzymes. While the expression level of SRD5A1 and SRD5A3 increased during prostate cancer progression (from benign to metastatic
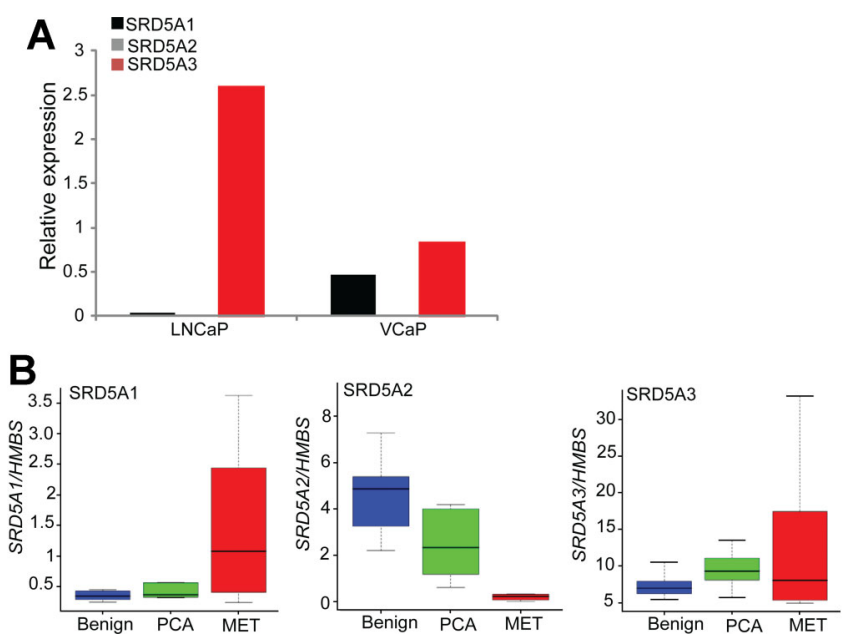

Fig. I. Expression of $5 \alpha$-reductases in prostate cancer cell lines and tissue samples. A: Quantitative SYBR green RT-PCR of $5 \alpha$-reductase isoforms SRD5AI, SRD5A2, and SRD5A3 in ETS fusion-positive cell lines LNCaP and VCaP. B: Box plot depicting expression levels of three isoforms of $5 \alpha$-reductase in benign prostate tissue, primary prostate cancer and metastatic prostate cancer samples ( $\mathrm{n}=8$ for each class). disease), there was a concurrent decrease in SRD5A2 (Fig. 1B). Consistent with the cell line studies, SRD5A3 expression was higher than SRD5A1 across all stages of the prostate cancer development (Fig. 1B).

To evaluate the effect of dutasteride on VCaP cell proliferation and viability, the cells with varying doses of dutasteride for $48 \mathrm{hr}$. Upon treatment the $\mathrm{VCaP}$ cells underwent morphological changes exhibiting spindle like phenotype (Fig. 2A, inset). No significant change in the cell number at lower doses of dutasteride treatment were observed, however there was a significant decrease in cell proliferation at $10 \mu \mathrm{M}(P=0.03)$ and a marked decrease at $50 \mu \mathrm{M}$ $(P=0.002$; Fig. $2 \mathrm{~A})$. These results suggest a growth inhibitory effect of dutasteride on the TMPRSS2-ERG fusion positive $\mathrm{VCaP}$ cell line.

We next tested the effect of dutasteride on cell invasion using Matrigel-coated Boyden chamber invasion assay. VCaP cells were treated with dutasteride alone, or in combination with $\mathrm{T}$ and DHT. As shown in Figure 2B, both DHT and T treatment resulted in a marked increase in cell invasion $(P=0.007$ and $P=0.02$, respectively) and treatment with the synthetic androgen, R1881, displayed the highest level ( $>5$-fold) of invasive phenotype (Fig. 2B; $P=0.001$ ). Importantly, dutasteride treatment significantly reduced the T- or DHT-mediated cell invasion (Fig. 2B; $P=0.03$ and $P=0.02$, respectively). These results clearly demonstrate the effectiveness of dutasteride in attenuating the invasive potential of ERGpositive prostate cancer cells.

\section{Dutasteride Inhibits the Expression of TMPRSS2-ERG Level in Fusion Positive VCaP Cells}

To evaluate the effect of dutasteride on TMPRSS2$E R G$ expression, $\mathrm{VCaP}$ cells were treated with dutasteride, $\mathrm{T}$ or DHT alone, or pre-incubated with dutasteride before treating with T or DHT. Quantitative real-time PCR analysis showed significant reduction in the TMPRSS2-ERG fusion transcript with $50 \mu \mathrm{M}$ of dutasteride treatment alone compared to vehicle-treated serum starved $\mathrm{VCaP}$ cells (Fig. 3A). We also observed a modest reduction in TMPRSS2$E R G$ fusion transcript in the VCaP cells pre-treated with dutasteride followed by $\mathrm{T}$ or DHT treatment compared to $\mathrm{T}$ or DHT treatment alone (Fig. 3A). Although dutasteride could further inhibit the basal level expression of ERG in androgen-depleted medium, we did not observe a concurrent reduction in the ERG protein in the cells pre-treated with dutasteride followed by T or DHT treatment (Fig. 3B). Treatment with $\mathrm{T}$ or DHT alone resulted in the induction of TMPRSS2-ERG fusion transcript as well as PSA and 


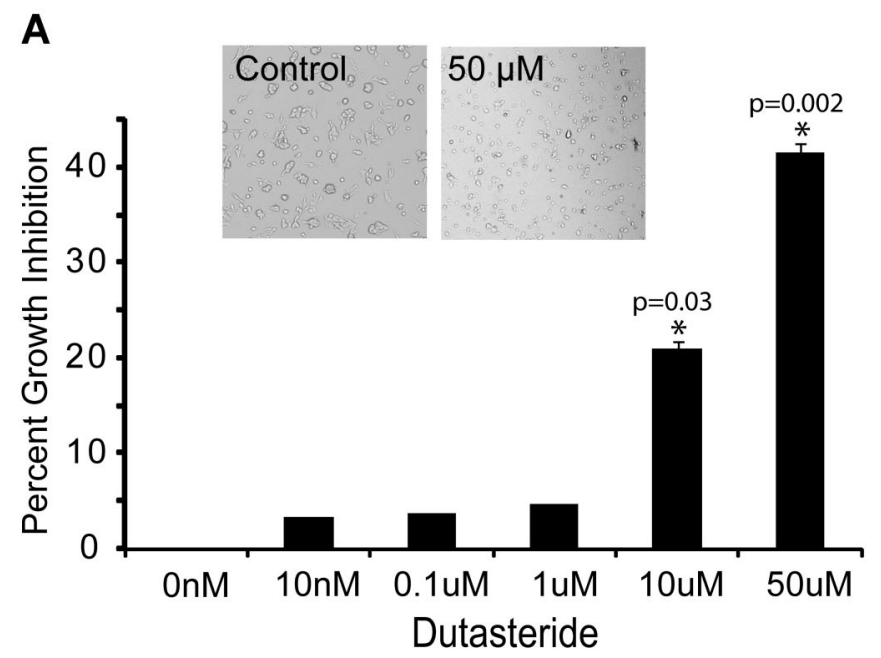

B

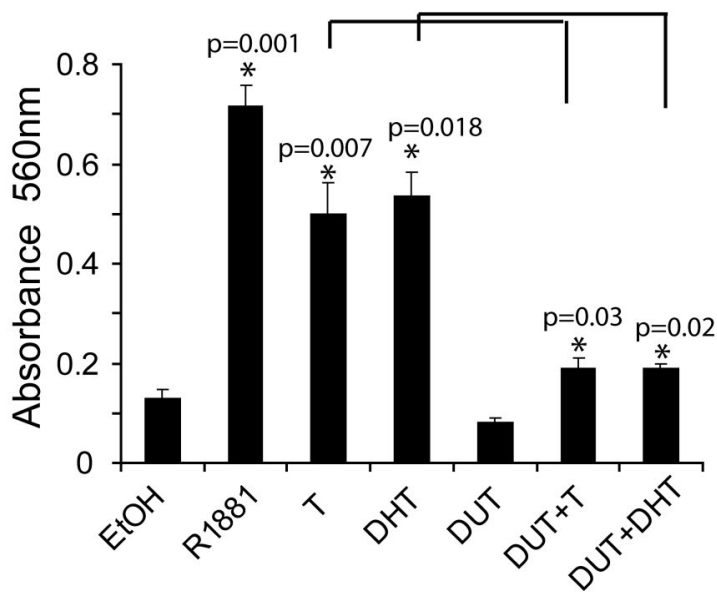

Fig. 2. Dutasteride inhibits VCaP cell proliferation and invasion. A: Cell proliferation assay using VCaP cells treated with varying concentrations of dutasteride. Photomicrograph of untreated and $50 \mu \mathrm{M}$ dutasteride treated cells are shown in the inset. B: Boyden Chamber Matrigel invasion assay showing invasive potential of $\mathrm{VCaP}$ cells under different experimental conditions as indicated.

ERG proteins as anticipated (Fig. 3A,B). These findings suggest that the inhibition of $\mathrm{T}$ conversion to DHT was not effective in blocking the fusion gene expression. In addition, we observed a significant increase in T converting enzymes SRD5A1 and SRD5A2 upon dutasteride treatment (Fig. 3C), suggesting a possible effect of $\mathrm{T}$ itself on the induction of fusion gene as well as the possible residual conversion to DHT.

\section{Dutasteride in Combination With Bicalutamide ReducesTumor Growth inTMPRSS2-ERG Positive Xenograft Model}

Next, we investigated the potential of dutasteride to inhibit tumor growth using an in vivo $\mathrm{VCaP}$ xenograft model system. We administered dutasteride alone or in combination with the anti-androgen, bicalutamide, to immunodeficient mice that were implanted with VCaP-luc cells subcutaneously. Three weeks later mice with pre-established tumors were randomized into four groups and were treated with dutasteride $(0.1 \mathrm{mg} / \mathrm{kg}$ body weight), bicalutamide (12 mg/ $\mathrm{kg}$ body weight), or a combination of both daily five times a week. Dutasteride alone was unable to demonstrate any significant anti-tumor effect, less than $20 \%$ reduction in tumor burden was recorded in this group. Likewise, bicalutamide treatment demonstrated about $30 \%$ reduction in tumor burden when administered alone $(P=0.007$ and $P=0.01$ at weeks 6 and 7, respectively). However, a combination of dutasteride and bicalutamide resulted in a significant reduction in tumor growth $(\sim 55 \%$ reduction) compared to untreated (Fig. 4A; $P=0.0001$ and
$P=0.001$ at weeks 6 and 7 , respectively). Similar results were obtained using bioluminescence imaging (Fig. 4B) where a significant decrease in photon flux was recorded in the group treated with dutasteride and bicalutamide combination compared to single drug treatment group. These results suggest that the inhibition of the DHT converting enzyme by dutasteride, in combination with anti-androgen, could lead to a marked reduction in tumor growth.

\section{DISCUSSION}

The prostate cancer specific TMPRSS2-ERG fusion gene induces the overexpression of the oncogenic protein, ERG that facilitates tumor progression and serves as a potential therapeutic target. The direct inhibition of transcription factors such as ERG is difficult because of the lack of an enzymatic activity and inaccessibility due to nuclear localization. However, blocking the function of regulatory proteins like AR may be more feasible as expression of the fusion gene is activated by AR-androgen axis. Increasing evidence suggest that enhanced intratumoral androgen synthesis may be one cause of resistance to androgen deprivation therapy. A recent study indicated that men who underwent transperineal three-dimensional mapping (TP-3DM) biopsy of the prostate and received dutasteride treatment for at least 3 months before biopsy showed $\sim 24 \%$ decrease in the upstaging and/or upgrading of prostate cancer compared to the control group that did not receive dutasteride [21], demonstrating a potential role for dutasteride in tertiary chemoprevention. Another large-scale clinical trial showed that dutasteride reduced the risk of 

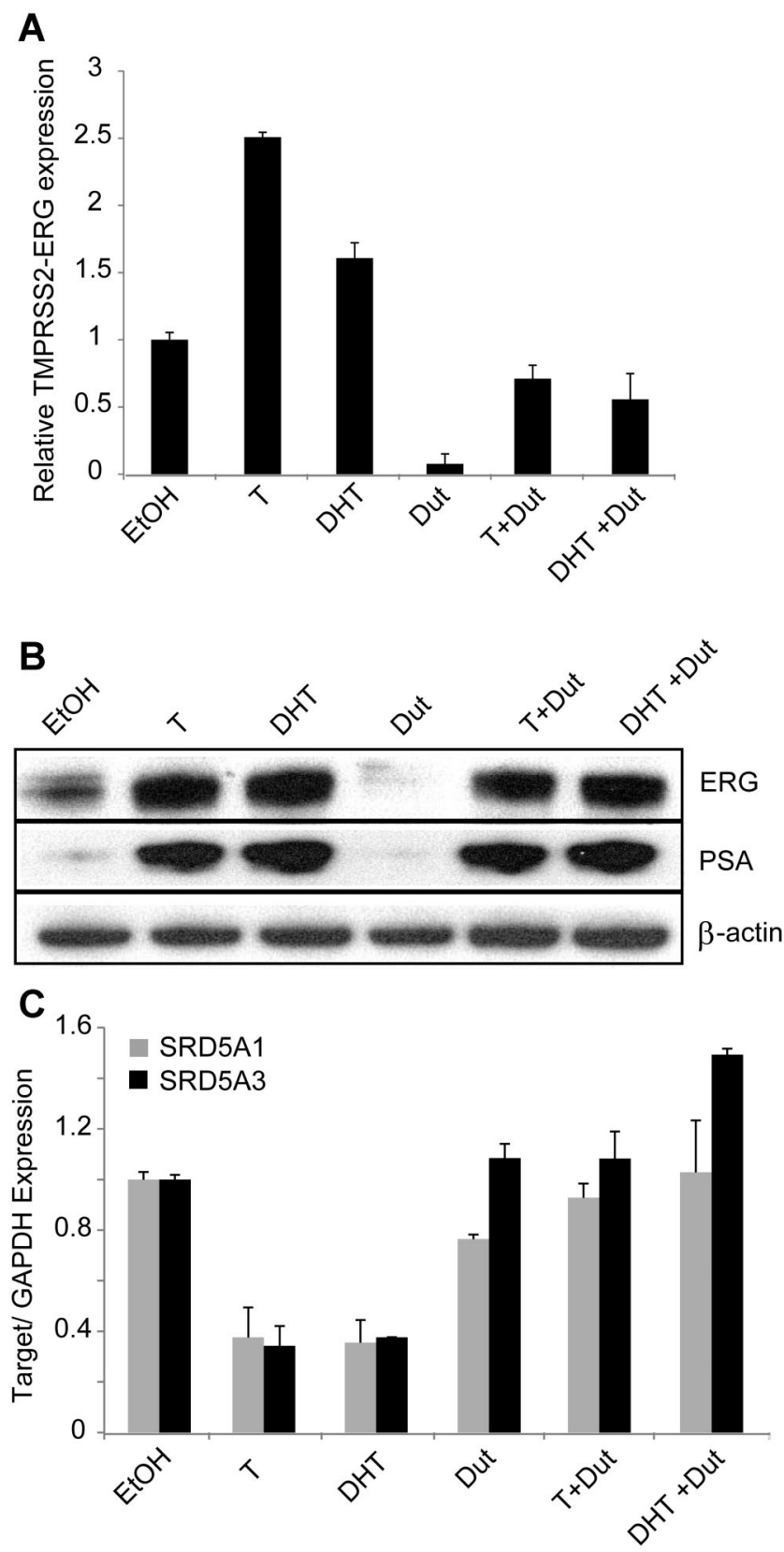

Fig. 3. Effect of dutasteride on PSA and ERG expression in VCaP cells. A: Quantitative SYBR green RT-PCR showing TMPRSS2-ERG fusion transcript expression in VCaP cells treated with ethanol, DHT, orT alone and/or in the presence of dutasteride. B: Experimental groups same as in (A), except representative immunoblots are shown for the ERG and PSA protein expression. C: Quantitative SYBR green RT-PCR showing SRD5AI and SRD5A3 transcripts expression in VCaP cells treated with ethanol, $\mathrm{DHT}$, orT alone and/or in the presence of dutasteride as indicated.

incident prostate cancer detected on biopsy and improved the outcomes related to benign prostatic hyperplasia [22]. Further, combining dutasteride with a CYP17A1 inhibitor ketoconazole in CRPC had beneficial effects resulting in remarkable prolongation of
A

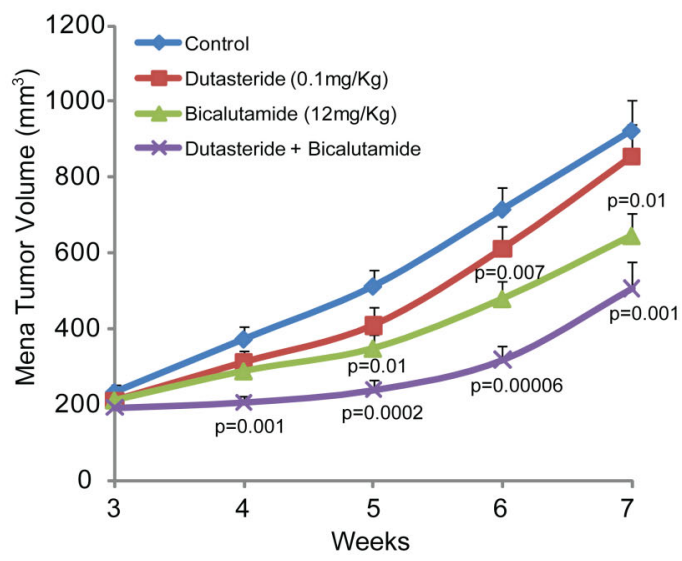

B Control Dutasteride Bicalutamide + Dutasteride
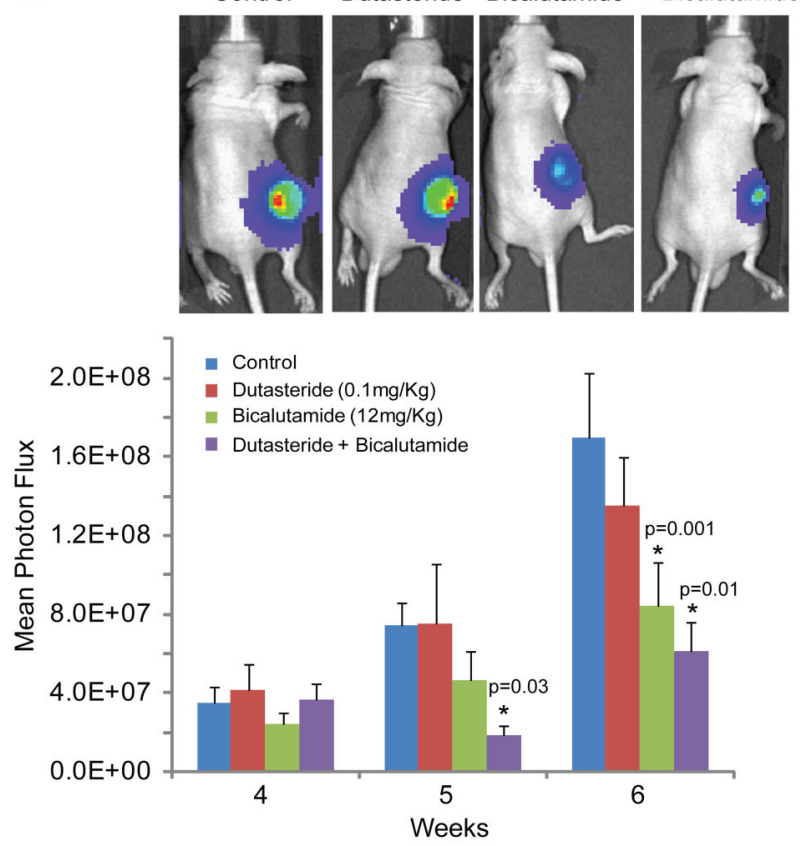

Fig. 4. Effect of dutasteride and bicalutamide combination theraPy on $\mathrm{VCaP}$ tumor growth. A: Line graph showing mean tumor volume recorded from the immunodeficient mice bearing subcutaneous VCaP-Luc xenografts. B: Experimental groups same as in (A), except bar graph showing mean photon flux. Representative bioluminescent images show mice bearing VCaP-Luc tumors at week 6.

progression time compared to single agent regimen [23]. However, the mechanism of dutasteride-mediated chemoprevention is not clearly understood.

Here, we analyzed the expression of three isoforms of $5 \alpha$-reductases in benign prostate and prostate cancer tissue samples and confirmed the increased expression of SRD5A1 and SRD5A3 in metastatic samples compared to benign and primary prostate cancer. A recent study indicated that SRD5A1 utilizes androstenedione as substrate in CRPC and converts it to DHT via an intermediate $5 \alpha$-androstanedione 
[15]. Therefore, we investigated the possibility of dutasteride-dependent inhibition of AR activity by blocking the conversion of T to DHT by $5 \alpha$-reductase. In addition, we also tested a combined therapy using the anti-androgen, bicalutamide, and the $5 \alpha$-reductase inhibitor, dutasteride.

Results of the current study demonstrate that dutasteride is effective in reducing the expression of the fusion gene TMPRSS2-ERG transcript even in the presence of T, but not at the protein level. Dutasteride inhibits cell proliferation and blocks the invasiveness of the fusion-positive $\mathrm{VCaP}$ cells in the presence of $\mathrm{T}$ or DHT. In addition, treatment with dutasteride in combination with anti-androgen reduces tumor burden significantly, demonstrating an additive tumor suppressive effect in the TMPRSS2-ERG fusion driven xenograft model. The mechanism underlying this additive effect is unclear and warrants further investigation. Our data suggest that dutasteride is only targeting one arm of the androgen pathway; hence, combining with other anti-androgens such as bicalutamide could be more beneficial compared to single agent treatment. Moreover, the recent identification of two diarylthiohydantoin compounds, RD162 and MDV3100, that bind to the AR with greater relative affinity than the bicalutamide could prove even more beneficial in combination therapy than the first generation anti-androgens [24].

In summary, our study provides a rationale for utilizing dutasteride, which has been extensively used for the symptomatic benign prostatic hyperplasia treatment, in combination with anti-androgens to treat TMPRSS2-ETS rearrangement-positive prostate cancer patients.

\section{ACKNOWLEDGMENTS}

We thank Dr. Arul M. Chinnaiyan and Dr. Roger Rittmaster for insightful discussions. We thank Jyoti Athanikar for critical reading of the article. S.V. is supported by a grant from GSK and B.A. is supported by a Genentech Foundation Postdoctoral Fellowship and Young Investigator Award from the Expedition Inspiration.

\section{REFERENCES}

1. Tomlins SA, Rhodes DR, Perner S, Dhanasekaran SM, Mehra R, Sun XW, Varambally S, Cao X, Tchinda J, Kuefer R, Lee C, Montie JE, Shah RB, Pienta KJ, Rubin MA, Chinnaiyan AM. Recurrent fusion of TMPRSS2 and ETS transcription factor genes in prostate cancer. Science 2005;310(5748):644-648.

2. Tomlins SA, Laxman B, Dhanasekaran SM, Helgeson BE, Cao X, Morris DS, Menon A, Jing X, Cao Q, Han B, Yu J, Wang L, Montie JE, Rubin MA, Pienta KJ, Roulston D, Shah RB, Varambally S, Mehra R, Chinnaiyan AM. Distinct classes of chromosomal rearrangements create oncogenic ETS gene fusions in prostate cancer. Nature 2007;448(7153):595-599.

3. Kumar-Sinha C, Tomlins SA, Chinnaiyan AM. Recurrent gene fusions in prostate cancer. Nat Rev 2008;8(7):497-511.

4. Tomlins SA, Laxman B, Varambally S, Cao X, Yu J, Helgeson BE, Cao Q, Prensner JR, Rubin MA, Shah RB, Mehra R, Chinnaiyan AM. Role of the TMPRSS2-ERG gene fusion in prostate cancer. Neoplasia 2008;10(2):177-188.

5. Sun C, Dobi A, Mohamed A, Li H, Thangapazham RL, Furusato B, Shaheduzzaman S, Tan SH, Vaidyanathan G, Whitman E, Hawksworth DJ, Chen Y, Nau M, Patel V, Vahey M, Gutkind JS, Sreenath T, Petrovics G, Sesterhenn IA, McLeod DG, Srivastava S. TMPRSS2-ERG fusion, a common genomic alteration in prostate cancer activates C-MYC and abrogates prostate epithelial differentiation. Oncogene 2008;27(40):53485353.

6. Klezovitch O, Risk M, Coleman I, Lucas JM, Null M, True LD, Nelson PS, Vasioukhin V. A causal role for ERG in neoplastic transformation of prostate epithelium. Proc Natl Acad Sci USA 2008;105(6):2105-2110.

7. King JC, Xu J, Wongvipat J, Hieronymus H, Carver BS, Leung DH, Taylor BS, Sander C, Cardiff RD, Couto SS, Gerald WL, Sawyers CL. Cooperativity of TMPRSS2-ERG with PI3-kinase pathway activation in prostate oncogenesis. Nat Genet 2009; 41(5):524-526.

8. Yu J, Mani RS, Cao Q, Brenner CJ, Cao X, Wang X, Wu L, Li J, Hu M, Gong Y, Cheng H, Laxman B, Vellaichamy A, Shankar S, Li Y, Dhanasekaran SM, Morey R, Barrette T, Lonigro RJ, Tomlins SA, Varambally S, Qin ZS, Chinnaiyan AM. An integrated network of androgen receptor, polycomb, and TMPRSS2-ERG gene fusions in prostate cancer progression. Cancer Cell 2010;17(5):443-454.

9. Gillatt D. Antiandrogen treatments in locally advanced prostate cancer: Are they all the same? J Cancer Res Clin Oncol 2006;132(Suppl 1):S17-S26.

10. Ang JE, Olmos D, de Bono JS. CYP17 blockade by abiraterone: Further evidence for frequent continued hormone-dependence in castration-resistant prostate cancer. Br J Cancer 2009;100(5): 671-675.

11. Nacusi LP, Tindall DJ. Targeting 5alpha-reductase for prostate cancer prevention and treatment. Nat Rev Urol 2011;8(7):378384

12. Bartsch G, Rittmaster RS, Klocker H. Dihydrotestosterone and the concept of 5alpha-reductase inhibition in human benign prostatic hyperplasia. World J Urol 2002;19(6):413-425.

13. Tindall DJ, Rittmaster RS. The rationale for inhibiting 5alphareductase isoenzymes in the prevention and treatment of prostate cancer. J Urol 2008;179(4):1235-1242.

14. Uemura $M$, Tamura $K$, Chung S, Honma S, Okuyama A, Nakamura $Y$, Nakagawa $H$. Novel 5alpha-steroid reductase (SRD5A3, type-3) is overexpressed in hormone-refractory prostate cancer. Cancer Sci 2008;99(1):81-86.

15. Chang KH, Li R, Papari-Zareei M, Watumull L, Zhao YD, Auchus RJ, Sharifi N. Dihydrotestosterone synthesis bypasses testosterone to drive castration-resistant prostate cancer. Proc Natl Acad Sci USA 2011;108(33):13728-13733.

16. Olsson Gisleskog P, Hermann D, Hammarlund-Udenaes M, Karlsson MO. Validation of a population pharmacokinetic/ pharmacodynamic model for 5alpha-reductase inhibitors. Eur J Pharm Sci 1999;8(4):291-299.

17. Fleshner NE, Lucia MS, Egerdie B, Aaron L, Eure G, Nandy I, Black L, Rittmaster RS. Dutasteride in localised prostate cancer 
management: The REDEEM randomised, double-blind, placebo-controlled trial. Lancet 2012; [Epub ahead of print].

18. Mostaghel EA, Geng L, Holcomb I, Coleman IM, Lucas J, True LD, Nelson PS. Variability in the androgen response of prostate epithelium to 5alpha-reductase inhibition: Implications for prostate cancer chemoprevention. Cancer Res 2010;70(4):12861295.

19. Kleer CG, Cao Q, Varambally S, Shen R, Ota I, Tomlins SA, Ghosh D, Sewalt RG, Otte AP, Hayes DF, Sabel MS, Livant D, Weiss SJ, Rubin MA, Chinnaiyan AM. EZH2 is a marker of aggressive breast cancer and promotes neoplastic transformation of breast epithelial cells. Proc Natl Acad Sci USA 2003; 100(20):11606-11611.

20. Tomlins SA, Mehra R, Rhodes DR, Smith LR, Roulston D, Helgeson BE, Cao X, Wei JT, Rubin MA, Shah RB, Chinnaiyan AM. TMPRS S2: ETV4 gene fusions define a third molecular subtype of prostate cancer. Cancer Res 2006;66(7):33963400.

21. Barqawi AB, O'Donnell CI, Siomos VJ, Hou AH. The effect of short-term dutasteride intake in early-stage prostate cancer:
Analysis of 148 patients who underwent three-dimensional prostate mapping biopsy. Urology 2010;76(5):1067-1071.

22. Andriole GL, Bostwick DG, Brawley OW, Gomella LG, Marberger M, Montorsi F, Pettaway CA, Tammela TL, Teloken C, Tindall DJ, Somerville MC, Wilson TH, Fowler IL, Rittmaster RS. Effect of dutasteride on the risk of prostate cancer. New Engl J Med 2010;362(13):1192-1202.

23. Taplin ME, Regan MM, Ko YJ, Bubley GJ, Duggan SE, Werner L, Beer TM, Ryan CW, Mathew P, Tu SM, Denmeade SR, Oh WK, Sartor O, Mantzoros CS, Rittmaster R, Kantoff PW, Balk SP. Phase II study of androgen synthesis inhibition with ketoconazole, hydrocortisone, and dutasteride in asymptomatic castration-resistant prostate cancer. Clin Cancer Res 2009; 15(22):7099-7105.

24. Tran C, Ouk S, Clegg NJ, Chen Y, Watson PA, Arora V, Wongvipat J, Smith-Jones PM, Yoo D, Kwon A, Wasielewska T, Welsbie D, Chen CD, Higano CS, Beer TM, Hung DT, Scher HI, Jung ME, Sawyers CL. Development of a second-generation antiandrogen for treatment of advanced prostate cancer. Science 2009;324(5928):787-790. 